
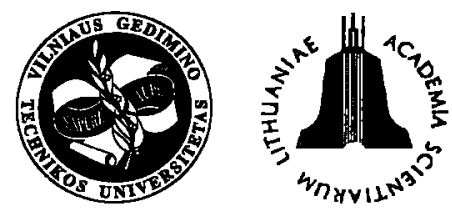

TRANSPORT

http:/www.vtu.lt/english/editions

TRANSPORT - 2002, Vol XVII, No 1, 3-7

\title{
ANALYSIS OF LOCOMOTIVE WHEEL SETS WEARING
}

\author{
Šarünas Mikaliūnas' ${ }^{1}$, Leonas Povilas Lingaitis ${ }^{2}$, Rimantas Subačius ${ }^{3}$ \\ Department of Railway Transport, Vilnius Gediminas Technical University, J. Basanavičiaus g. 28, LT-2009 Vilnius, \\ Lithuania, Tel. (22) 233-844 \\ Received 200112 04; accepted 20011219
}

\begin{abstract}
Wearing dynamics of traction rolling-stock wheel tyres of diesel locomotives was investigated. Based on research results it is possible to predict wheel-tyre safety margin, to improve maintenance and state periodicity of repair, as well as to use traction rolling-stock repair funds most efficiently.

Keywords: railway, locomotive, wheel-set, wearing, wheel-set flange, lubrication, wearing intensity, prediction of wearing
\end{abstract}

\section{Introduction}

The locomotive wheel-sets are major components of the running gear. This is one of the most heavily wearing units often requiring expensive repairs. Rolling stock safety and uniform motion largely depend on their performance. Therefore it is extremely important to determine the intensity of the wheel-set wearing at various stages of their service life.

The analysis of the above characteristics will enable us to determine more accurately the safety margin of the wheel tyres and the supply of spare wheel sets needed by a locomotive park, as well as to establish the optimal servicing and repair intervals allowing more efficient allocation of expenses on rolling stock repair.

\section{Research object and aims}

As wheel tyres are wearing out the running surface profile of the wheel is gradually losing a conical shape. Wearing action causes the formation of a groove (a cut) on the surface of the wheel flange.

The wearing of the wheel tyres is caused by two factors. The first is plastic deformation when the metal is forced out from the running surface towards the flange. The second is thermal effect taking place in wheel spinning or when stopping the locomotive. This causes the formation of a hard martensite structure on the running surface.

Heavy deformations of the wheel tyres and railhead occur due to long - term wheel and rail interaction. In this case, cyclic effect of contact stresses can cause a residual

\footnotetext{
1'E-mail: smikal@ti.vtu.lt,smikal@takas.lt

2E-mail: leonas1@ti.vtu.lt

${ }^{3}$ E-mail: rimantas@ti.vtu.lt
}

deformation. Though it can not completely destroy the wheel tyre, normal operation may be disturbed by vibration and dynamic loads.

The dimensions of the wheel tyre change depending on the wear of the running surface which is determined by a cut size (i) (Fig 1) as well as by the reduction of the flange width (a) (known as natural wearing). This also depends on the removal of a metal layer while recovering the thickness and height of the flange by turning the wheel tyre and its running surface (known as technological wear), being, therefore, determined by the general intensity of wearing.

The formation of a cut (i) in the wheel tyre is caused by the plastic deformation of metal occurring under normal forces. The second factor is the separation of the wheel

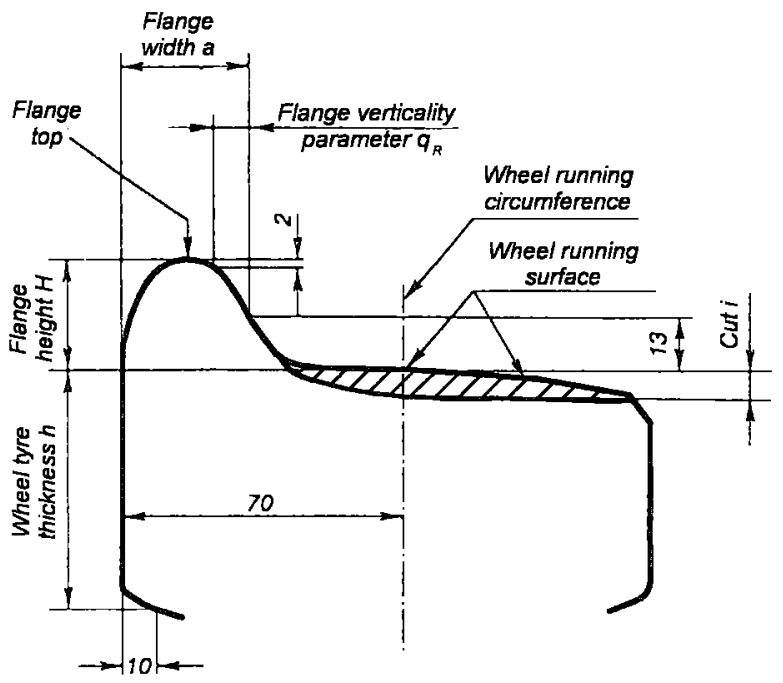

Fig 1. Profile of the wheel running surface and the parameters verified 
metal particles under friction. The value of the normal force depends on the locomotive construction while friction intensity is determined by upright pressure and the values of the coupling coefficient.

A major factor affecting the flange (a) wear is its sliding relative to the rail during the movement of the locomotive when it is either approaching the profile plane of the rail bead or departing from it $[1,2]$.

Due to the $(10 \mathrm{~mm})$ gap between the flange and the rail head the wheel-sets are swaying. Regular wheel tyre flange movement towards and away from the rail is a major cause of their intensive wear.

The wearing of the locomotive wheel-sets is also caused by a number of minor factors, i.e. chemical composition of the wheel tyres, physical properties and uniformity of the metal used, quality of manufacture, strength factors, climatic conditions, loading conditions, operation under maximum load, air temperature, humidity and dust content, the pollution of wheel-tyre surfaces with abrasive materials (e. g. putting sand between the wheels and rails), track condition determining the dynamic load intensity, speed of the locomotive, lubrication of the contact points of the wheel and the rail, etc.

It is hardly possible to distinguish a single most important factor among listed above. This would require special research to establish the effect of a particular factor on the wheel-set wear. Such investigations could be rather complicated as well as requiring special equipment and research conditions.

Wheel-sets and tyres are not manufactured in Lithuania, being imported from other countries. Therefore we can not make any influence on technological solutions and structural factors increasing wheel tyre strength. But we can determine the nature of wheel-set wearing under various service conditions (i. e. road section, loading, speed, flange operational conditions, etc.).

In order to reduce the wearing of the wheel tyre flanges a lubrication system should be provided in a locomotive. One of such systems is FluiLub - wheel tyre lubrication system made by Baier + Köppel, a German firm. It supplies oil to the tyre flange when the locomotive is running along the curved track sections, with the most heavy friction between the flange and the rail. Depending on the direction of the locomotive movement the flanges of the front wheel-sets of every locomotive section are lubricated.

The trials $[3,4]$ performed did not yield any relationships concerning the wearing intensity of the wheel tyre flanges and the running surfaces during their service life $[5,6]$. Therefore, currently accepted intervals between the repairs of the wheel-sets by turning them are not rational as well as being practically unpredictable. This is one of the reasons why the railroad companies experience additional losses from not timely turning the wheel-sets or due to the decrease of their durability caused by the removal of a layer of metal in this operation. The main objective of the present research is to determine major trends of wheelsets wearing in order to be able to predict repair intervals, as well as determining their distance run between overhauls allowing to plan the number of repairs and spare wheel-sets to be purchased.

\section{The experiment}

For experimental purposes two locomotives 2M62 (each of them having 12 wheel-sets in two sections), not provided with wheel tyre lubrication systems, and one locomotive 2M62 having a German Baier + Köppel FluiLub system to lubricate tyre flanges were chosen.

At the beginning of the experiment all the wheel-sets were new with their tyre dimensions conforming to the rated parameters given in Table 1.

Table 1. Verified dimensions of wheel tyre profile

\begin{tabular}{|c|c|c|c|}
\hline $\begin{array}{c}\text { Dimensionsv- } \\
\text { erified }\end{array}$ & $\begin{array}{c}\text { The } \\
\text { largestwheel } \\
\text { tyre cut } i, \\
\mathrm{~mm}\end{array}$ & $\begin{array}{c}\text { Flange width } \\
a, \mathrm{~mm}\end{array}$ & $\begin{array}{c}\text { Wheel } \\
\text { tyrethickness } \\
h, \mathrm{~mm}\end{array}$ \\
\hline Initial (rated) & 0 & 33.0 & 77.0 \\
\hline Limiting & 7 & 25.0 & $36^{*}$ \\
\hline
\end{tabular}

* This thickness of the wheel tyre is reached when its running surface is turned to recover the required profile when the flange is heavily worn - out (with a $<25.0 \mathrm{~mm}$ ).

The measurements of the wearing wheel tyre profile were made every month when the locomotive returned to the depot for maintenance or repair. The average distance nun between the measurements of the locomotives not provided with a wheel tyre lubrication system was $10785 \mathrm{~km}$, while for those having such systems it reached $10504 \mathrm{~km}$.

The locomotive wheel-sets were measured in the locomotive depot in Vilnius in 1999-2000.

The intensity of wearing of the locomotive wheel tyres and their flanges in particular largely depends on the extent of track curvature. Therefore the locomotives being investigated ran along the tracks with the curvature radius common to Lithuanian railroads. The radii of the curved tracks of Lithuania are given in Table 2.

From Table 2 we can see that the relationship between straight and curved railroad sections in Lithuania is 1:3.

It was assigned that oiled and not oiled wheel tyres would operate under the same conditions, i.e. running along the same track sections. The work performed by them (tkm brutto) should also be the same, while both sections of each locomotive would always operate simultaneously.

\section{Measurement techniques}

Measurements of the cut in the wheel tyre and the width of its flange were made by a gauge following "The 
Table 2. Lithuanian railway length distribution based on track curvature radius

\begin{tabular}{|l|l|}
\hline Straight sections, $\mathrm{km}$ & 1809.2 \\
\hline $\begin{array}{l}\text { Curved sections, km, with the radius } \\
\text { of curvature being: } \\
-<300 \mathrm{~m}\end{array}$ & 4.8 \\
$-300-350 \mathrm{~m}$ & 3.9 \\
$-351-500 \mathrm{~m}$ & 16.8 \\
$-501-650 \mathrm{~m}$ & 88.9 \\
$-651-800 \mathrm{~m}$ & 61.7 \\
$-801-1000 \mathrm{~m}$ & 109.9 \\
$-1001-1200 \mathrm{~m}$ & 94.9 \\
$-1200 \mathrm{~m}$ & 220.5 \\
Total: curved sections, $\mathrm{km}$ & 601.4 \\
\hline Total length of major roads, km & 2410.6 \\
\hline
\end{tabular}

Instruction for the formation, repair and maintenance of the wheel-sets of $1520 \mathrm{~mm}$ wide gauge line railway rolling stocks".

The scheme of measuring the wheel tyre cut and flange width is given in Fig 2.

The basic surfaces used in measuring the width of the wheel tyre flange and the cut are as follows: the inside upright surface of the wheel tyre and the flange top, which do not vary in operation.

The width of the flange (a) - distance measured along the horizontal $20 \mathrm{~mm}$ below the flange top (Fig 2).

The difference between the measured flange height and that of the new or turned flange determines the size of the cut (i), caused by wearing, with respect to the running wheel circumference.

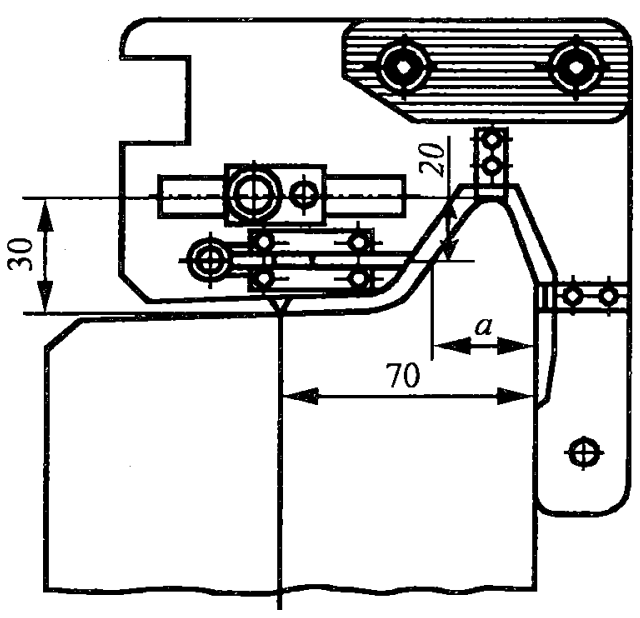

Fig 2. Scheme of flange width measurement
The cut is measured in the plane of the running wheel circumference, being $70 \mathrm{~mm}$ away from the inside wheel tyre surface [7].

Each wheel tyre was measured at three points along the perimeter with the following data recorded about it in a measurement log: the largest cut size and the smallest flange width, i.e. the largest values of the wear were fixed.

During the experiment the mileage of a locomotive between the beginning of the experiment and each measurement was also logged.

The following wheel tyre parameters were verified: wheel tyre cut (i) and flange width (a).

When measuring the cut the gauge accuracy was $\pm 0.1 \mathrm{~mm}$, while for the wheel tyre flange measurement it was $\pm 0.3 \mathrm{~mm}$.

\section{The obtained results}

In the experimental period, the highest mileage for the wheel-sets not provided with a lubrication system was $135509 \mathrm{~km}$, while for those having a lubrication system it reached $141648 \mathrm{~km}$.

The values obtained for the parameters verified with the fixed mileage values are random variables. Therefore the dependence of these parameters on mileage is determined by means of a regressive analysis. The direction line reveals the trend and the character of the change of this sequence of data. With the help of Excel 97 software package the polynomials - mathematical expression of curves - were calculated. In this way the data were processed and the following regression equations obtained:

- for the cut:

without lubrication:

$i=-7 \cdot 10^{-11} \cdot L^{2}+3 \cdot 10^{-5} \cdot L$,

with lubrication:

$$
i=5 \cdot 10^{-11} \cdot L^{2}+10^{-5} L
$$

graphical representation of these data is shown in Fig 3;

- for flange wearing intensity:

without lubrication:

$$
A=5 \cdot 10^{-15} \cdot L^{3}-10^{-9} \cdot L^{2}+0,0001 \cdot L \text {, }
$$

with lubrication:

$$
A=2 \cdot 10^{-15} \cdot L^{3}-6 \cdot 10^{-10} \cdot L^{2}+7 \cdot 10^{-5} \cdot L \text {, }
$$

here $i$ - is the cut, $\mathrm{mm} ; L$ - mileage, $\mathrm{km} ; A$-intensity of flange wear, $\mathrm{mm}$. Fig 4.

The curves representing flange wearing are given in

The comparison of the data obtained shows that the intensity of wear of the locomotive wheel tyre flanges is twice as high as that of the cut formation. Thus, the wearing of wheel tyre flanges is the main factor determining the time between wheel tyre overhauls.

It is possible to state that lubrication has no significant effect on the rate of cut formation (Fig 3).

The regression equations obtained also show that 


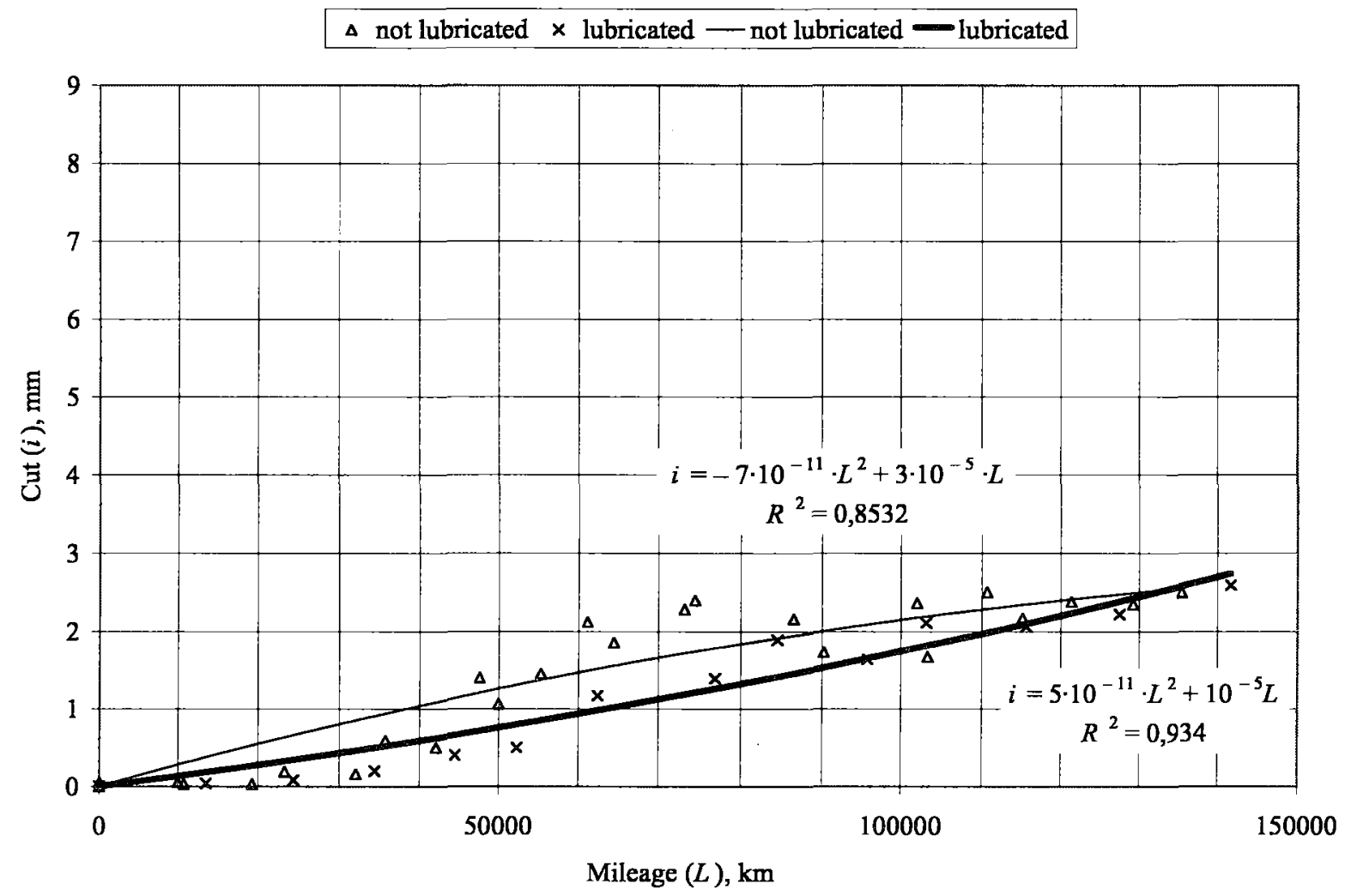

Fig 3. Dependence of wheel cut value on mileage

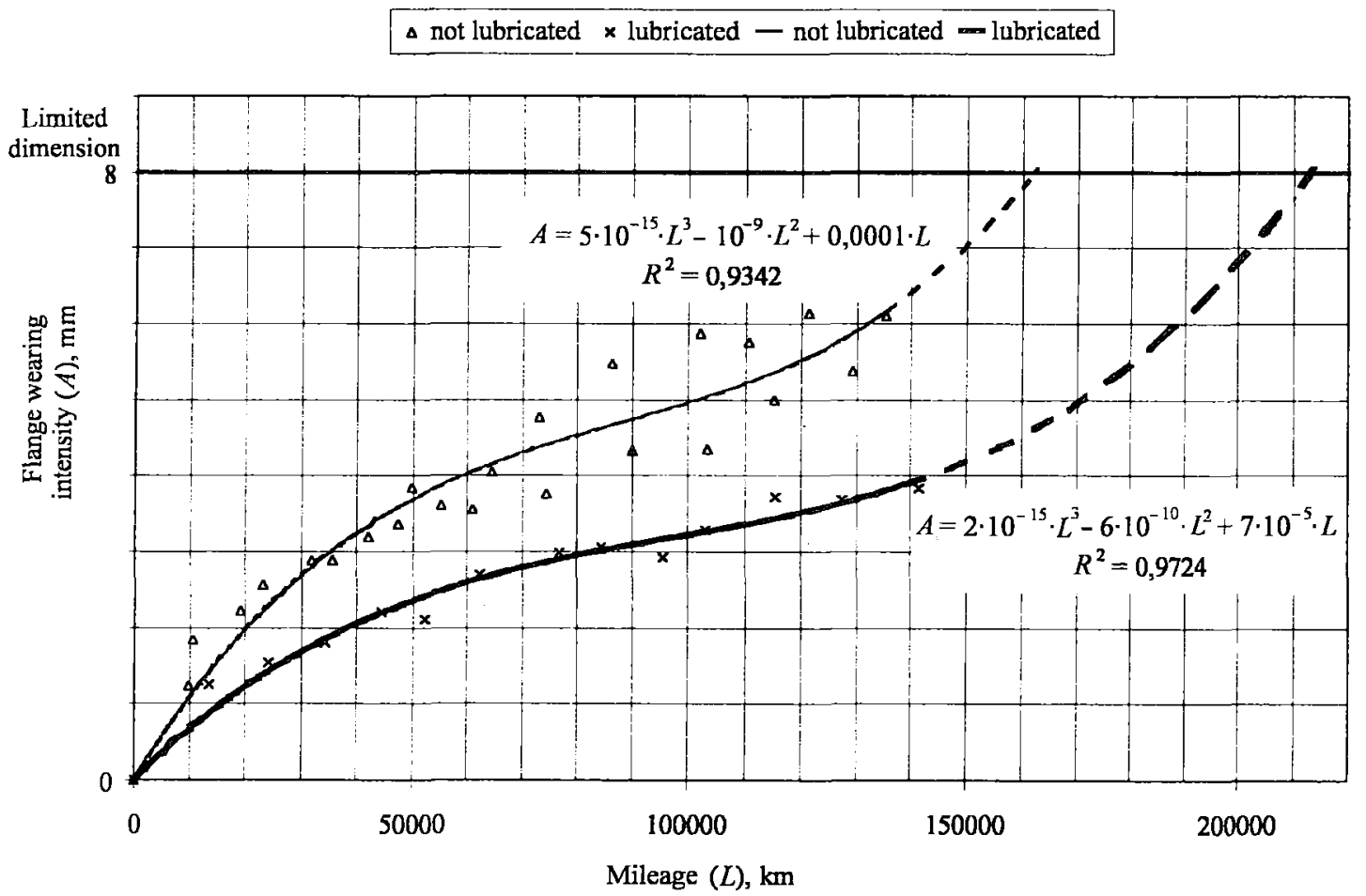

Fig 4. Intensity of wheel flange wearing 
the cut is increasing uniformly throughout the total service period, while the flange wearing (Fig 4) is most intensive at the beginning of service until the mileage reaches $30000-40000 \mathrm{~km}$, with the worn-out layer being $1.5-2.5$ $\mathrm{mm}$. This proves a well-known fact that more intensive flange wearing takes place until the wheel tyre profile acquires the shape of the rail head $[6,8,9]$. Then the intensity of wear decreases, increasing only when the mileage comes up to $150000 \mathrm{~km}$.

The relationships obtained allow us to predict that turning of the wheel-sets because of worn-out flanges should be performed when the mileage of $160000 \mathrm{~km}$ is reached since the beginning of service of the wheel tyres, not provided with a lubrication system. When wheel tyre flanges are lubricated the limit is $210000 \mathrm{~km}$. The accuracy of the calculated data is $\pm 2 \%$ (with $95 \%$ probability). Thus, it may be stated that the use of lubrication system can increase wheel tyre service life by at least 1.3 times.

\section{Conclusions}

1. The investigation has shown that the flange is wearing out more intensely at the beginning of service till the mileage of $30000-40000 \mathrm{~km}$ is reached with the wornout layer being $1.5-2.5 \mathrm{~mm}$. Then the wearing action slows down, further increase taking place when $150000 \mathrm{~km}$ has been run.

2. The wearing intensity of the flange of the locomotive wheel tyres is about two times heavier than the increase of the cut, therefore the time between wheel-sets overhauls is determined by the extent of flange wear.

3. It is possible to predict that the flange will be worn out to the limiting width after running $160000 \pm 3000 \mathrm{~km}$ without lubrication and after $210000 \pm 4000 \mathrm{~km}$ of mileage if it is lubricated.

4. The provision of a lubrication system for the wheel set flanges increases the mileage of the wheel-sets until turning is needed up to $31 \%$.

\section{References}

1. Kurasov D. A. Povyshenije dolgovecnosti bandazei kolesnych par podviznogo sostava. Moskva: Transport, 1981. $160 \mathrm{~s}$. (in Russian).

2. Wrang M. Single-axle running-gear. Stockholm: Royal institute of technology, 1995. $136 \mathrm{p}$.

3. Grieve D. G., Dwyer-Joyce R. S., Beynon J. H. Abrasive wear of railway track by solid contaminants. Journal of Rail and Rapid Transit, Vol 215, 2001, p. 193 - 205.

4. Gnedenko B. V. , Beliajev J. K., Solovjov A. D. Matematichieskije metody $\mathrm{v}$ teoriji nadioznosti. Moskva: Nauka, 1965. 367 s. (in Russian).

5. Zhai W. M., SunX. A detailed model for investigating vertical interactions between railway vehicle and track. Vehicle System Dynamics, Vol 23 (Suppl.), 1994, p. 603-615.

6. Moreau A. Characteristics of wheel/rail contact. Rail Engineering. International Edition, 1992, No 3, p. $15-22$.

7. $1520 \mathrm{~mm}$ pločio vèžès traukos riedmenu aširačių formavimo, remonto ir priežiūros instrukcija. Vilnius: L G informacijos ir leidybos centras, 1999.128 p. (in Lithuanian).

8. Wu T.X., Thompson D. J. Theoretical investigation of wheel/ rail non-linear interaction due to roughness excitation. Vehicle System Dynamics, Vol 34 (4), 2000, p. 261 - 282.

9. Gurule S., Wilson N. Simulation of whee1/rail interaction in turnouts and special track work. Vehicle System Dynamics, Vol 33, 1999, p. $143-154$. 